\title{
MINERALS FROM THE REPUBLIC OF MACEDONIA WITH AN INTRODUCTION TO MINERALOGY
}

\author{
by \\ Gligor Jovanovski, Blažo Boev and Petre Makreski \\ with continued contributions from Branko Kaitner, Trajče Stafilov and Bojan Šoptrajanov
}

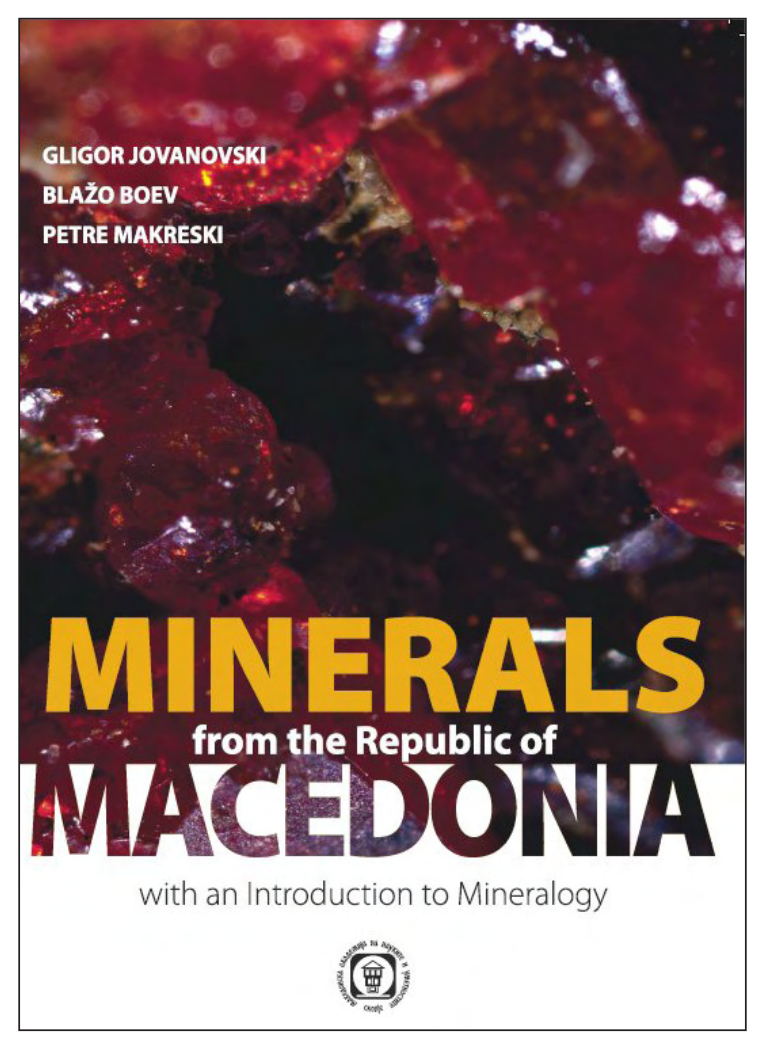

The reviewed monograph is the first extended work in which data on the minerals of the Republic of Macedonia have been described. This book is written in English to make the information on the mineralogy of the Republic of Macedonia accessible to a worldwide audience. The monograph contains a general introduction to mineralogy, which makes it useful for people starting their education in this science, i.e. students of geology, amateur mineralogists and mineral collectors in the Republic of Macedonia. Thus, the monograph is a dual-purpose book.

The first part of the book is an introduction to mineralogy with the necessary connections to the related sciences of physics, chemistry and crystallography. The starting point is the keystone: what a mineral is, what mineralogy is and how minerals are formed. Furthermore, we see material on the crystallographic basis of mineralogy and a chapter devoted to the crystalline state of substances. The next point is on the chemistry of minerals. This significant chapter explains modern conceptions on the constitution of solids and the types of chemical bonds. An important part of the basis of mineralogy is the theory of isomorphism and solid solutions, which is also reflected in the monograph. The physical properties of minerals and an introduction to optical mineralogy are found in the next chapter. A long chapter is devoted to modern methods of mineralogical research, including physical assays such as X-ray diffraction and various spectroscopic methods as well as chemical analysis. The final chapter of the first part of the book presents the principles of the classification of minerals and some examples.

The second main part of the monograph contains collected information on the minerals of the Republic of Macedonia and their localities. A chapter is devoted to the general geological characteristics of the Republic of Macedonia. The four major geotectonic units of the territory, namely the West-Macedonian zone, the Pelagonian massif, the Vardar zone and the Serbo-Macedonian massif are described, focusing on mineragenetic aspects.

The next chapter seems especially valuable, as it includes a description of the most interesting mineral localities of the Republic of Macedonia (with a geographical map showing their distribution). This information was almost unknown to the worldwide community of both professional and amateur mineralogists and the monograph mainly fills in this blank. Among others, the descriptions of localities of global mineralogical significance are given. First, there is the famous Allchar, an unusual lowtemperature hydrothermal Au-Sb-As deposit with incredibly rich and diverse thallium mineralization, a source of many new minerals and the location of a unique project on solar neutrinos. Alinci is a very 
interesting location, as it is a group of alkali-syenite related occurrences: a new mineral, macedonite, or $\mathrm{PbTiO}_{3}$, was first discovered here and several rare species have been found. Nežilovo, a belt of metamorphic and metasomatic rocks with unusual mineralogy and geochemistry, similar to the famous Långban in Sweden, is also described, focusing on the distribution of exotic complex oxygen compounds with $\mathrm{Pb}, \mathrm{Ba}, \mathrm{Zn}, \mathrm{Mn}, \mathrm{Sb}, \mathrm{Ti}, \mathrm{As}$, etc., with endogene origin. Other outstanding objects characterized in the book are an ultrabasic complex with nickel deposits at Ržanovo, a polymetallic deposit related to manganese-rich skarns at Sasa, as well as the occurrence of nice, big crystals of pink corundum and even ruby in the marbles at Sivec. From the monograph, we can learn about remarkable finds of giant crystals at localities in the Republic of Macedonia such as epidote (up to 1 $\mathrm{m})$, titanite, gypsum, etc.

The next chapter comprises of mineral descriptions where all mineral species and varieties known in the Republic of Macedonia are listed. The minerals are divided in two groups: the first, much larger group, is related to the studied and characterised minerals by the authors of the monograph, whereas the second group contains information concerning the non-collected minerals (in the monograph termed as other minerals). For each mineral, general data (chemical formula, symmetry, physical properties, occurrence, origin of the name, etc.) and information on its distribution in the Republic of Macedonia are given. Furthermore, for the studied minerals, quantitative chemical composition analysis, X-ray powder diffraction data with determined unit cell parameters, optical data and infrared and/or Raman spectrum are given. These characteristics were obtained from mineral samples collected in the Republic of Macedonia.

The last chapter includes a list of publications of the authors on the mineralogy of the Republic of Macedonia and indices of minerals and localities mentioned in the monograph. It is necessary to note that each chapter of the book contains a detailed list of references that is valuable in itself.

An important part of the monograph is the illustrations. Besides common figures necessary to describe basic concepts (especially in the first part, the introduction to mineralogy), we can enjoy many color photographs of minerals from the Republic of Macedonia, including nice full-page pictures. This seems valuable because the mineral specimens from this country are not well-known and not widespread in foreign museums and private collections, and readers will acquire considerable new information and impressions from these pictures. The high printing quality of the book merits praise.

Thus, I can recommend this monograph to a wide audience, from professional mineralogists and geologists to people who are taking their first steps in this field.

Prof. Igor V. Pekov

Dept. of Mineralogy, Faculty of Geology, Lomonosov Moscow State University

Moscow, Russia

Publisher: Macedonian Academy of Sciences and Arts, Skopje, Macedonia

Co-publisher: Skenpoint, Skopje, Macedonia

http://mineralsfrommacedonia.blogspot.mk/ 


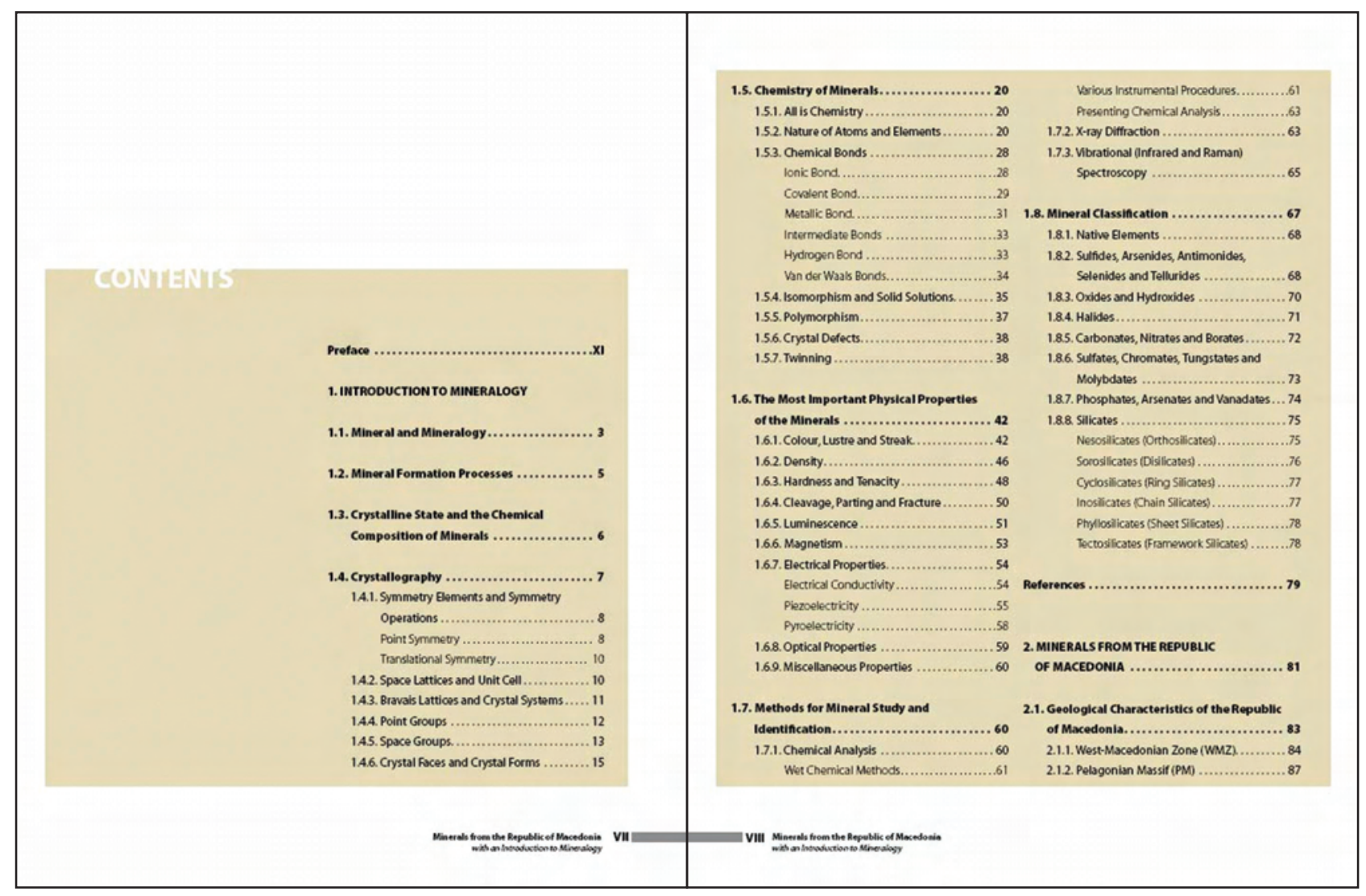

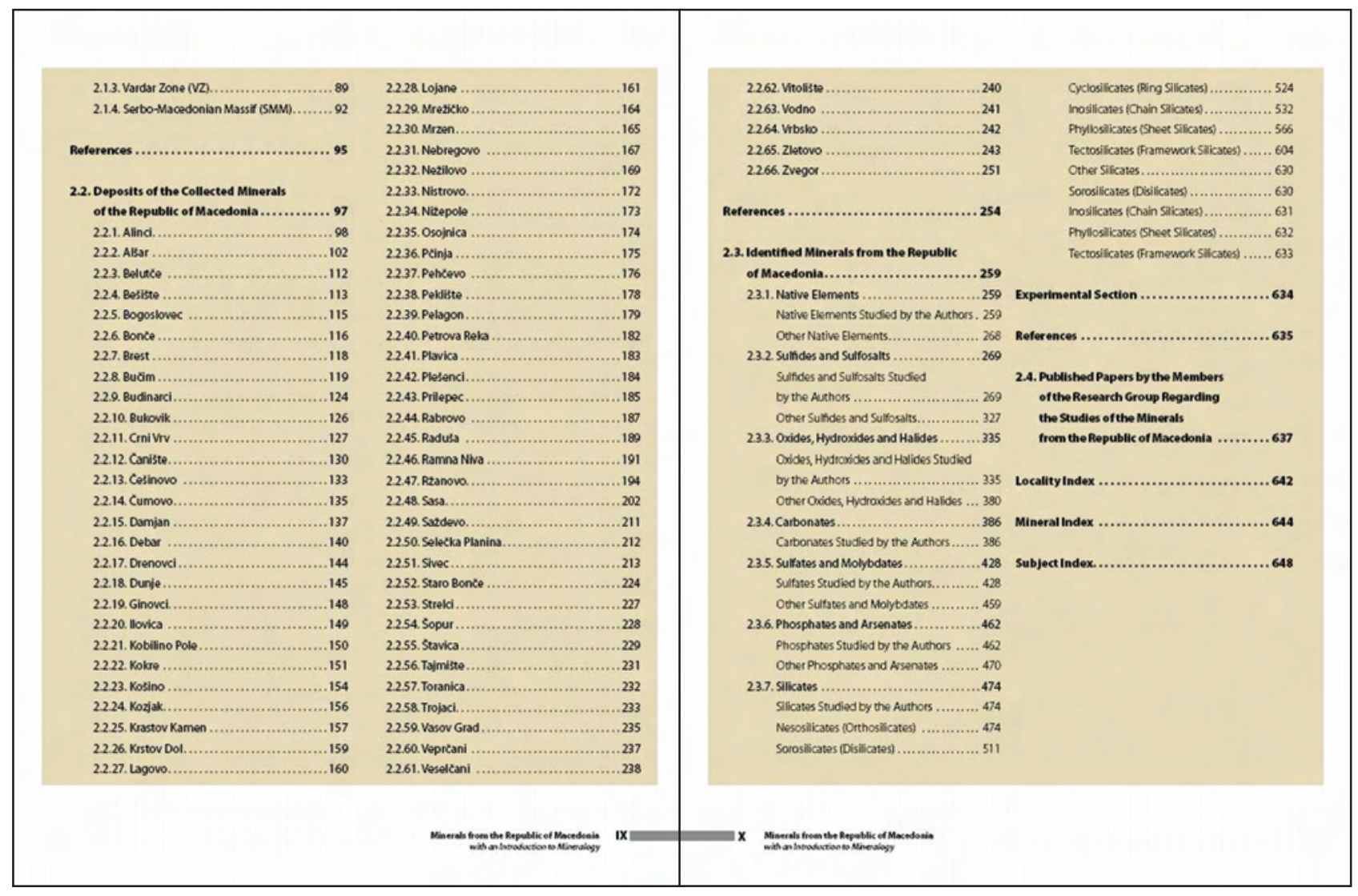



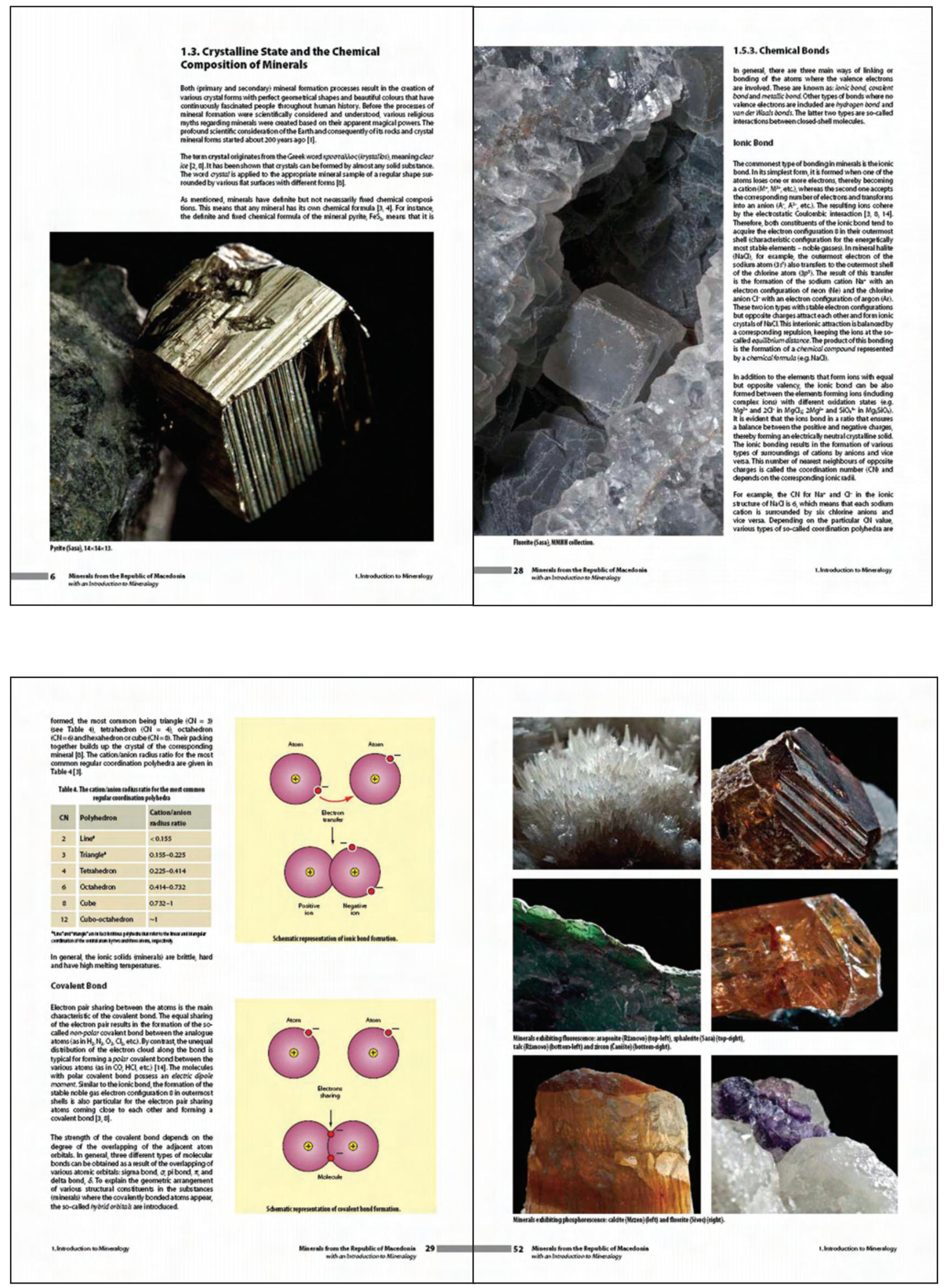

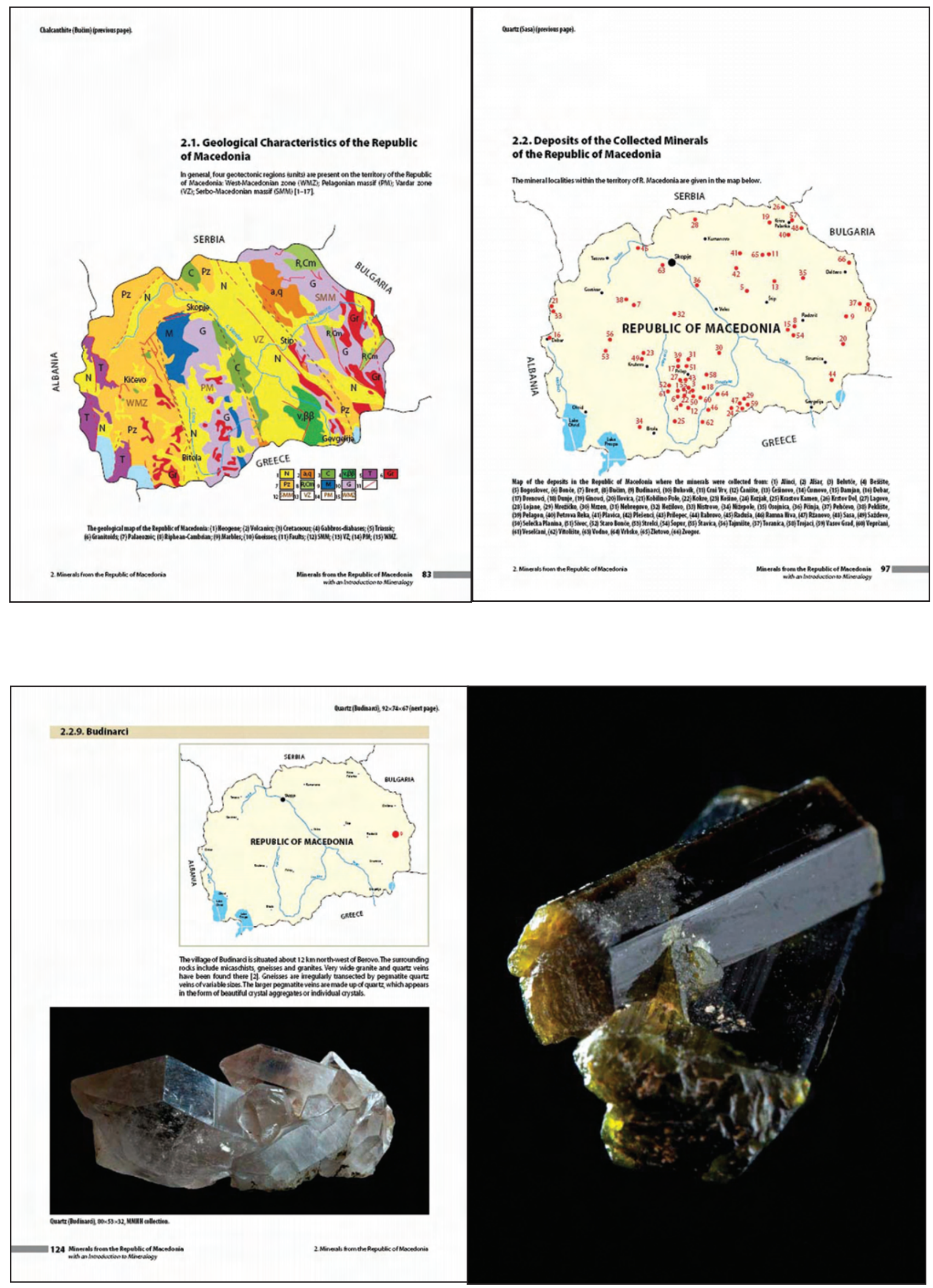

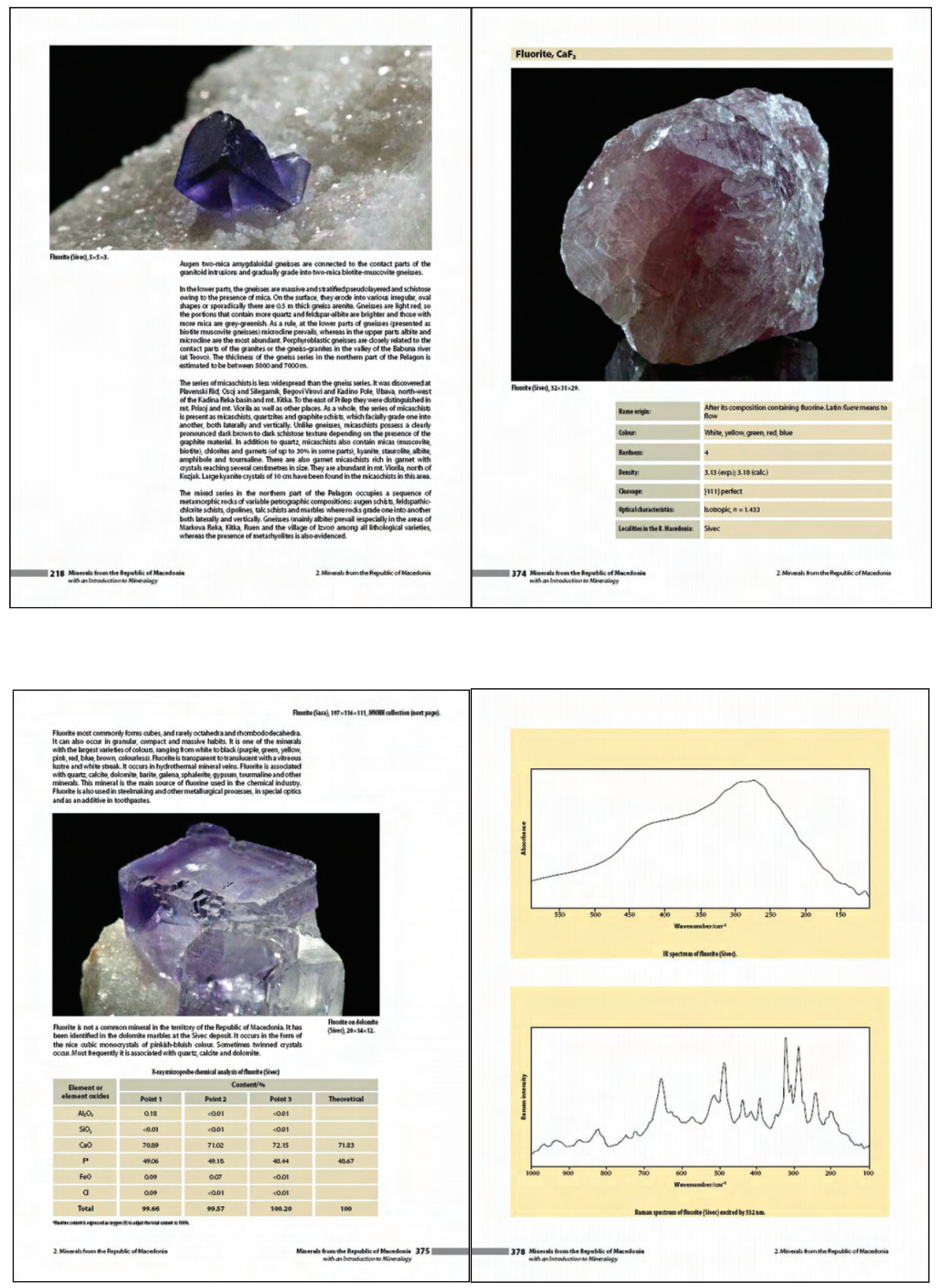

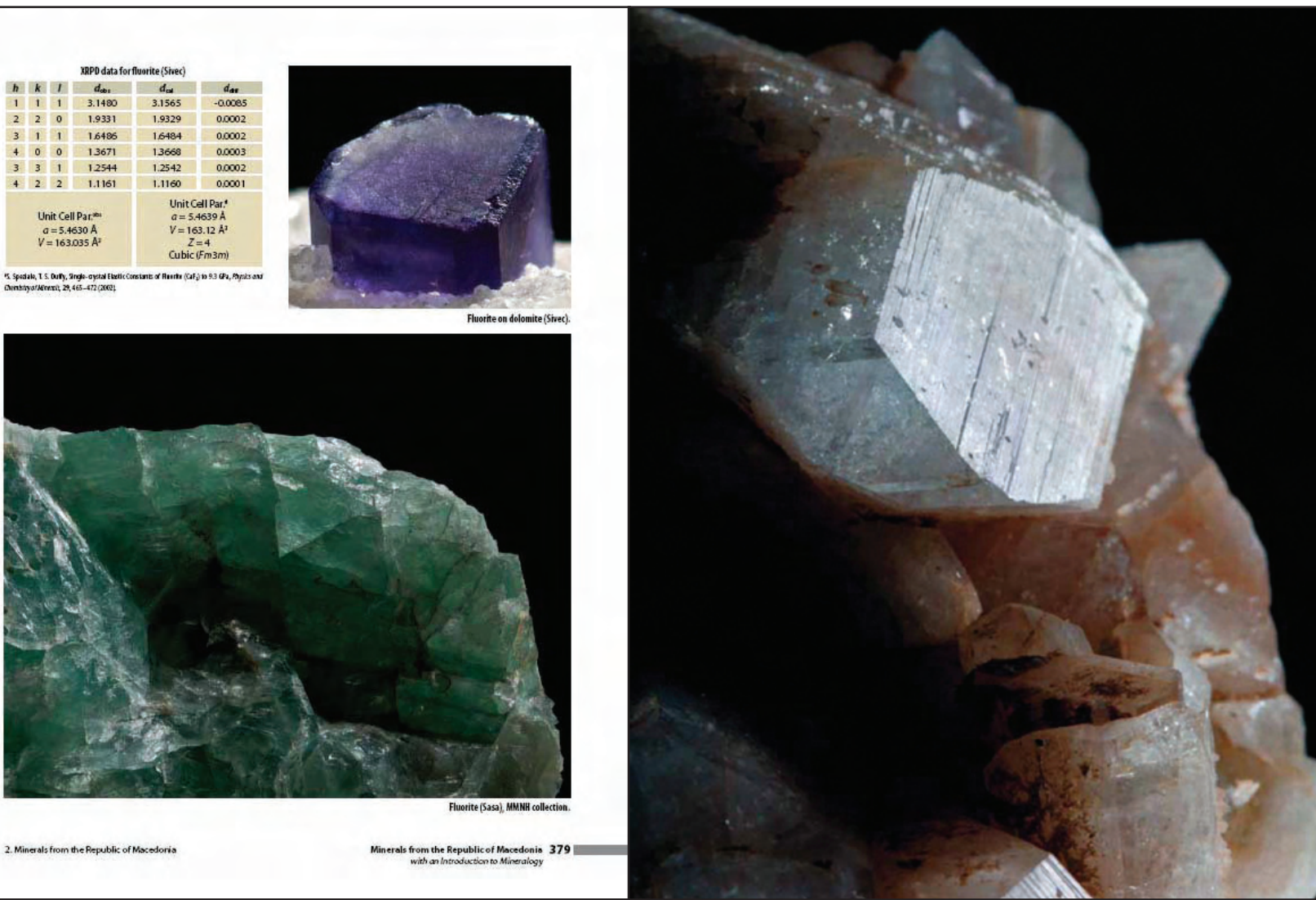

2.4. Published Papers by the Members of the Research Group Regarding the Studies of Minerals from the Republic of Macedonia

$$
\begin{aligned}
& \text { 1.t. }
\end{aligned}
$$

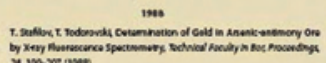

$$
\begin{aligned}
& \text { r. }
\end{aligned}
$$

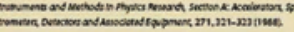

$$
\begin{aligned}
& 1 \text { \% }
\end{aligned}
$$

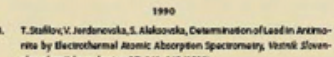

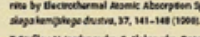

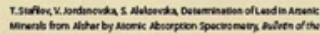

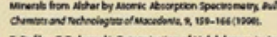

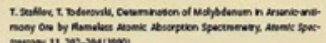

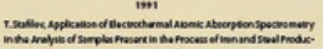

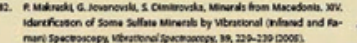

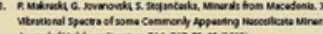

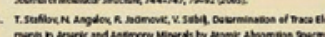

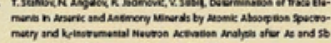

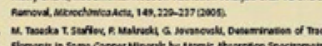

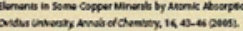

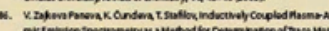

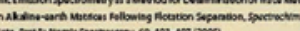

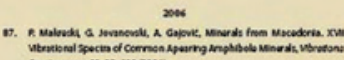

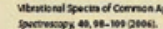

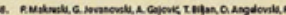

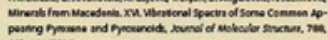

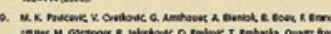

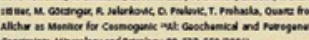

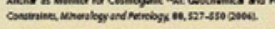

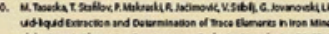
the

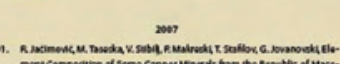

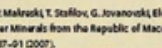

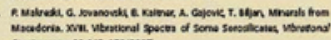

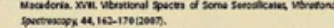

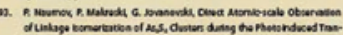

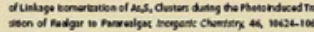
acosi

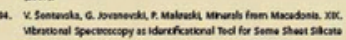

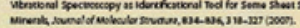

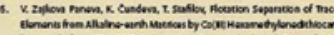

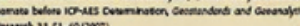

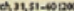

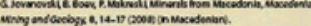

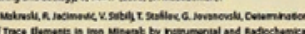

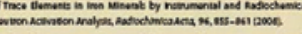

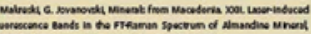

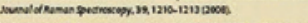

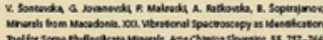

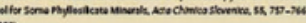

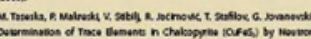

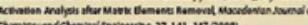

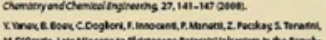

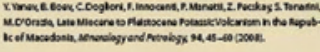

2000

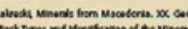

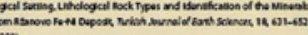

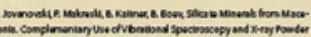

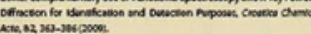

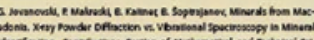

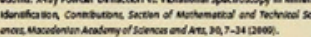

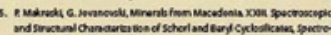

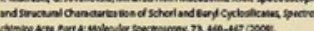

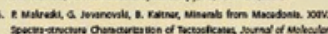

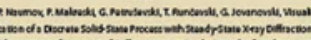

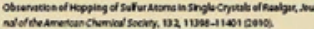

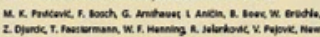

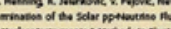

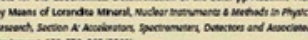

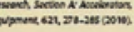

